\title{
WestVirginiaUniversity
}

THE RESEARCH REPOSITORY @ WVU

Graduate Theses, Dissertations, and Problem Reports

2018

\section{Survey for naturally occurring radioactive materials at a gas fractionation plant}

Brittany Diane Jones

Follow this and additional works at: https://researchrepository.wvu.edu/etd

\section{Recommended Citation}

Jones, Brittany Diane, "Survey for naturally occurring radioactive materials at a gas fractionation plant" (2018). Graduate Theses, Dissertations, and Problem Reports. 4000.

https://researchrepository.wvu.edu/etd/4000

This Problem/Project Report is protected by copyright and/or related rights. It has been brought to you by the The Research Repository @WVU with permission from the rights-holder(s). You are free to use this Problem/Project Report in any way that is permitted by the copyright and related rights legislation that applies to your use. For other uses you must obtain permission from the rights-holder(s) directly, unless additional rights are indicated by a Creative Commons license in the record and/ or on the work itself. This Problem/Project Report has been accepted for inclusion in WVU Graduate Theses, Dissertations, and Problem Reports collection by an authorized administrator of The Research Repository @ WVU. For more information, please contact researchrepository@mail.wvu.edu. 


\title{
Survey for Naturally Occurring Radioactive Material at a Gas Fractionation Plant
}

\author{
Brittany D. Jones \\ Problem Report submitted to \\ The Benjamin M. Statler College of Engineering and Mineral Resources \\ at West Virginia University
}

In partial fulfillment for the degree of

Master of Science in Industrial Hygiene

Dr. Steven Guffey Ph.D., CIH, Chair

Dr. Gary Winn Ph.D., CHST

Joshua Simmons MSPH, CIH, CSP

Department of Industrial and Management Systems Engineering (IMSE)

\author{
Morgantown, West Virginia
}

2018

Keywords: NORM, Naturally Occurring Radioactive Material, Marcellus Shale Copyright 2018 Brittany D. Jones 


\section{Abstract \\ Survey for Naturally Occurring Radioactive Material at a Gas Fractionation Plant Brittany Jones}

Marcellus Gas Company (MGC) is a midstream energy company operating natural gas gathering and processing assets in the Marcellus Shale region, primarily in Ohio, West Virginia, and Pennsylvania. At the time of the study, MGC was interested in surveying for naturally occurring radioactive material (NORM) at their primary fractionation facility in the region, the Ohio River Fractionation Plant. A NORM survey, consisting of over 300 measurements, was conducted at the site to evaluate the need to implement the company's written NORM program and to assess for additional controls to protect employees against ionizing radiation exposure. Additionally, a qualitative exposure assessment was performed to identify similar exposure groups and tasks with NORM exposure risk at the facility.

The site NORM survey identified several pieces of equipment with NORM readings over the company's internal limit, requiring implementation of additional controls for NORM. Following a review of the applicable regulations concerning NORM, as well as industry best practices, additional recommendations were made to MGC to protect employees from potential exposure to ionizing radiation. These recommendations include additional training, monitoring, and written program updates. 


\section{Acknowledgements}

I would like to sincerely thank my committee members for their time, insight, and patience over the years; words cannot express my gratitude. I would like to thank Joshua Simmons for encouraging me to take on this study, and providing me with resources to accomplish this project during my time at the company. I would also like to thank Marie Owen for her tireless support on the administrative side. Finally, I would like to thank the numerous colleagues who have provided feedback, answered my questions, and provided me support since I began this project; your kindness did not go unnoticed. 


\section{Table of Contents}

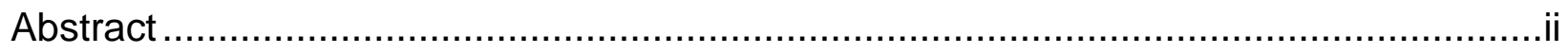

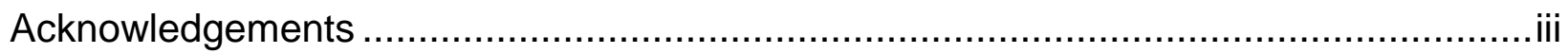

List of Figures

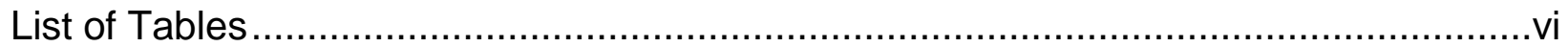

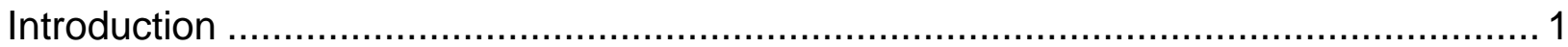

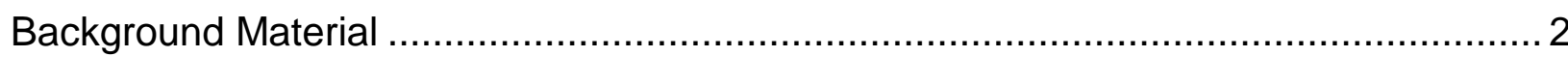

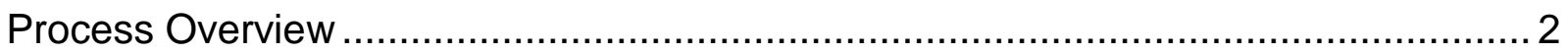

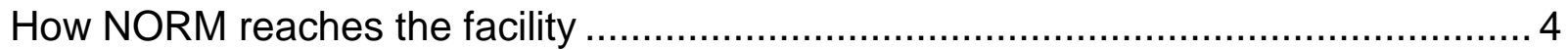

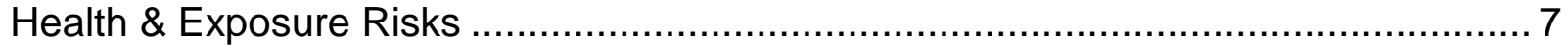

Exposure Monitoring for Alpha and Beta Emitters ……........................................ 9

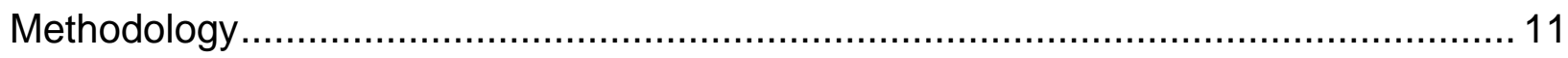

Facility Survey for Gamma Radiation............................................................ 11

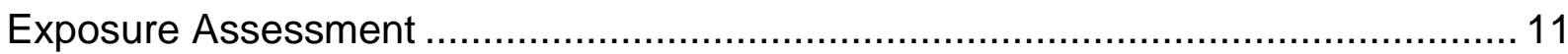

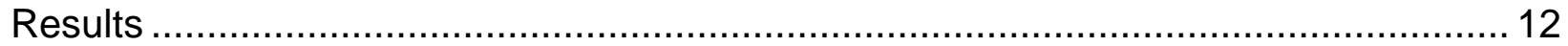

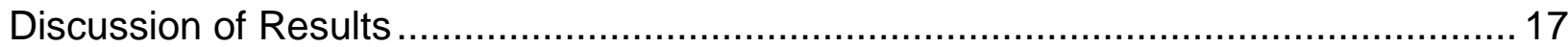

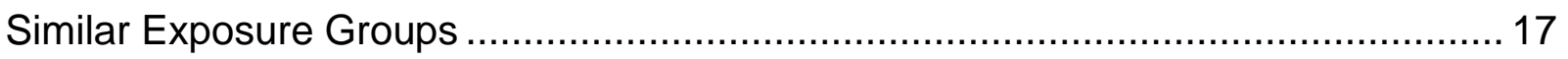

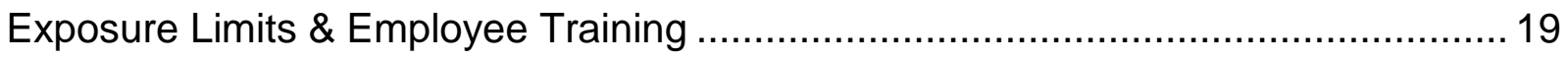

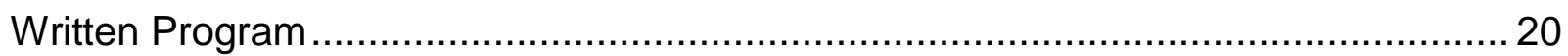

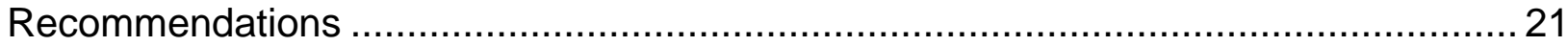

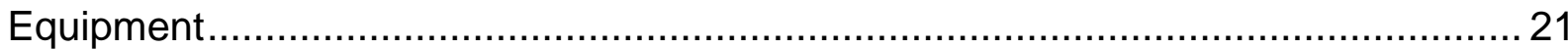

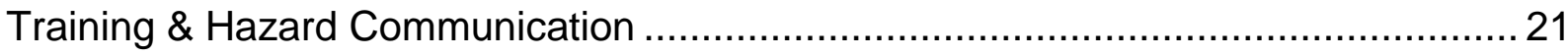

Written Program \& Procedures .................................................................... 22

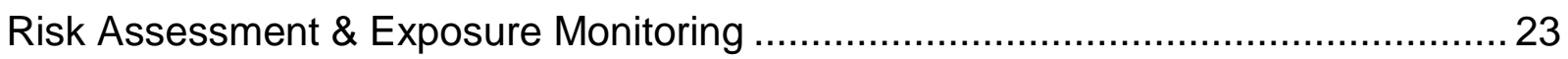

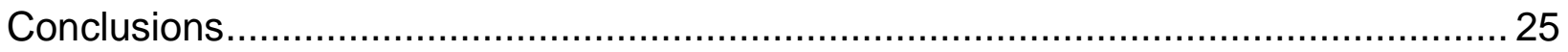

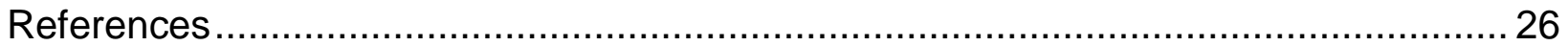




\section{List of Figures}

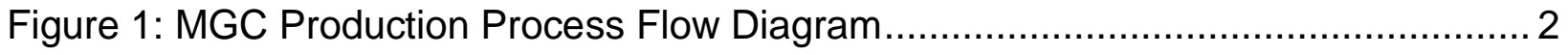

Figure 2: Reflux/Reboiler Loop Process Flow Diagram ............................................ 3

Figure 3: MGC Ohio River Fractionation Plant Process Flow Diagram ........................... 4

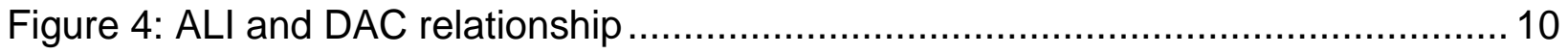

Figure 5: Depropanizer and Debutanizer Plot Plan ............................................... 14

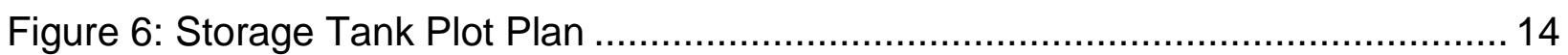




\section{List of Tables}

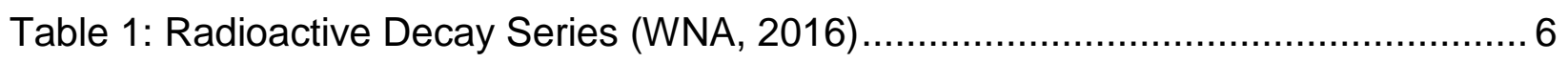

Table 2: Boiling Points of Feed Components ................................................................. 7

Table 3: NORM Readings for Depropanizer and Associated Equipment ...................... 12

Table 4: NORM Readings for Debutanizer and Associated Equipment ........................ 13

Table 5: NORM Readings for Product Storage …................................................. 15

Table 6: NORM Readings for Product Loading Area ............................................... 16

Table 7: Ohio River Fractionation Plant Similar Exposure Groups ............................... 17 


\section{Introduction}

A company hereafter referred to as "Marcellus Gas Company (MGC)" is an energy company who owns and operates midstream natural gas gathering and processing assets nationwide, including interstate pipelines for the transport of natural gas. At the time of this study the company had recently made a large acquisition in the Marcellus Shale region and was interested in surveying for naturally occurring radioactive material (NORM) at their primary fractionation facility in the region. The prior owner of the facility had operated the assets since 2009. The plant, here labelled the "Ohio River Fractionation Plant", was the location for this study. It was brought online in March 2012 and had been operating normally at the time of the study in July 2013. MGC operates the Ohio River Fractionation Plant in the Ohio River Valley region, which includes portions of Ohio, West Virginia, and Pennsylvania, but asked that the site's specific location be withheld for the purposes of this study.

The Marcellus and Utica Shale gas fields which feed the Ohio River Fractionation Plant is fed by a network of hydraulically fractured wells. The gas produced in these shale gas fields contains a high percentage of "wet gas" or "natural gas liquids" (NGLs) components, including ethane, butane, propane, and pentane. Wet gas requires additional processing to separate, market, and sell these valuable NGL components from the mixture. The remaining methane product is marketed and sold separately to natural gas customers as pipeline quality dry natural gas (Brockett, 2015). 


\section{Background Material}

\section{Process Overview}

The feed to the Ohio River Fractionation Plant comes from the nearby MGC Cryogenic Plant. The product coming into the MGC Cryogenic Plant is treated with multiple separation processes at both the well and at various in-line gathering field compressor stations along the pipeline system. These separation processes serve to remove produced well water and condensate material (often natural gasoline or heavier hydrocarbons) from the stream. The product is then treated using a glycol dehydration process to remove additional water in the MGC Cryogenic Plant before reaching a turboexpander (expandercompressor) where the feed is rapidly cooled to low temperatures. The turboexpander equipment separates the dry methane components of the gas for recompression, marketing, and sale to customers from the heavier natural gas liquids. The NGLs are run through a demethanizer train, including a fractionation column and reflux/reboiler loop, to remove any residual methane, and are then sent via pipeline to the Ohio River Fractionation Plant for additional separation and sale (Seddon, 2006 and Brockett, 2015). Figure 1 shows the basic steps of the overall separation process.

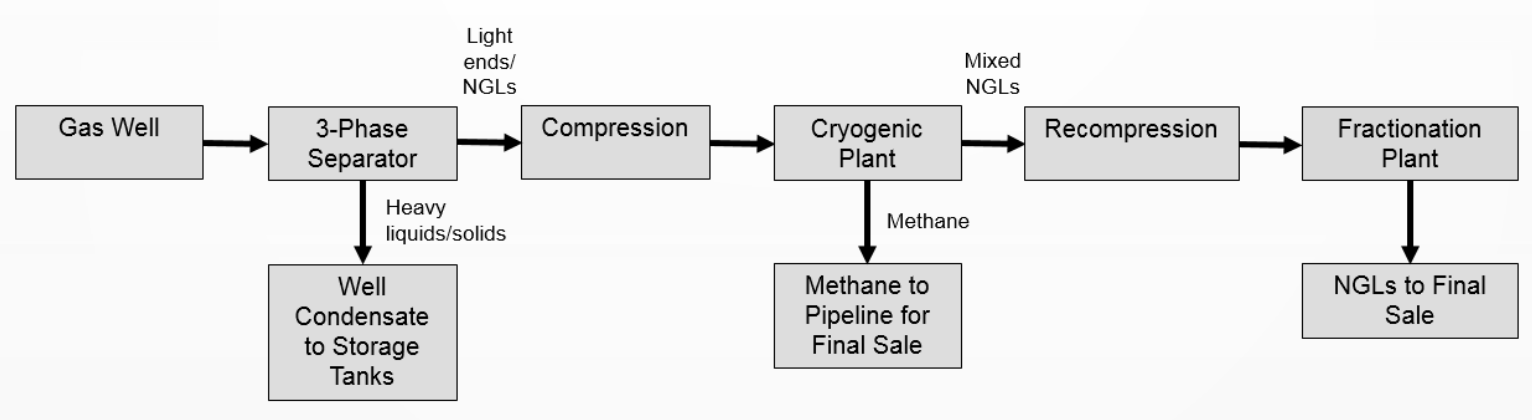

Figure 1: MGC Production Process Flow Diagram

Once the mixed NGL feed enters the Ohio River Fractionation Plant, it is filtered to remove particulate including pipeline corrosion components and consequentially NORM particulate from the feed. The feed then enters the NGL fractionation process where it travels through a series of fractionation towers, accumulators, and reboilers. The first process in the NGL fractionation series is depropanizing. In the depropanizing process, a fractionation column is first used to separate out the propane component from the mixed NGL feed entering the facility, using pressure and temperature to take advantage of the relative boiling points of the mixed feed. To improve recovery of propane from the mixed feed, a portion of the condensed overhead material is recycled from the overhead accumulator to the fractionation column as reflux to ensure that all recoverable propane is separated and no heavier hydrocarbons are being 
processed with the propane for storage and final sale. The reboiler is used to reheat a portion of the bottoms stream (butanes and heavier), which is also recycled back to the fractionation column for further separation, much like the reflux stream. (Leffler, 2008) This process is described graphically in Figure 2.

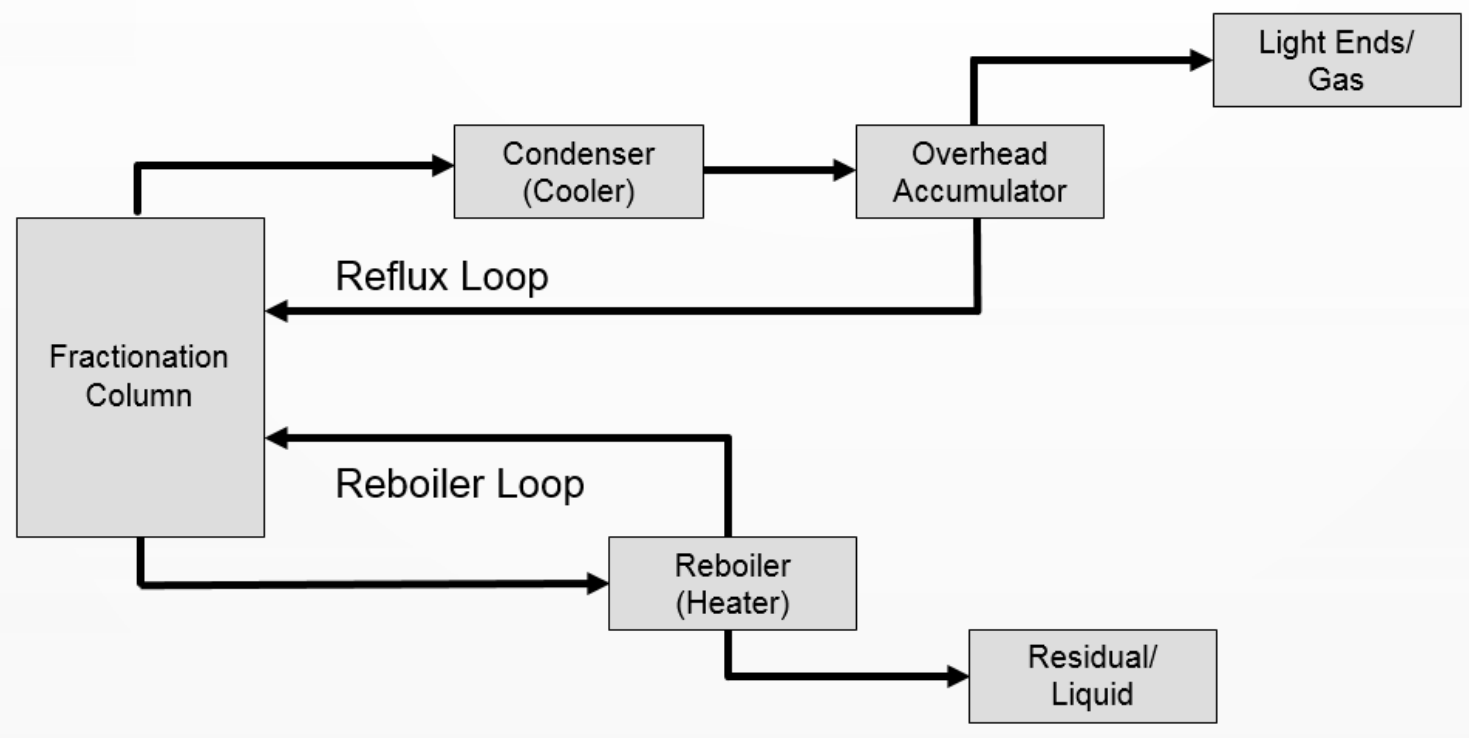

Figure 2: Reflux/Reboiler Loop Process Flow Diagram

Once the remaining mixed feed leaves the depropanizer process, it enters the debutanizer process, which operates at a higher temperature and pressure to remove butane from the remaining mixed feed. Using similar principles, the debutanizer also uses reflux/reboiler loops to ensure maximum recovery and quality of butane for storage and final sale before the remaining natural gasoline material (pentanes and heavier) travels to storage for sale to downstream customers for additional processing. This process is outlined in Figure 3. 


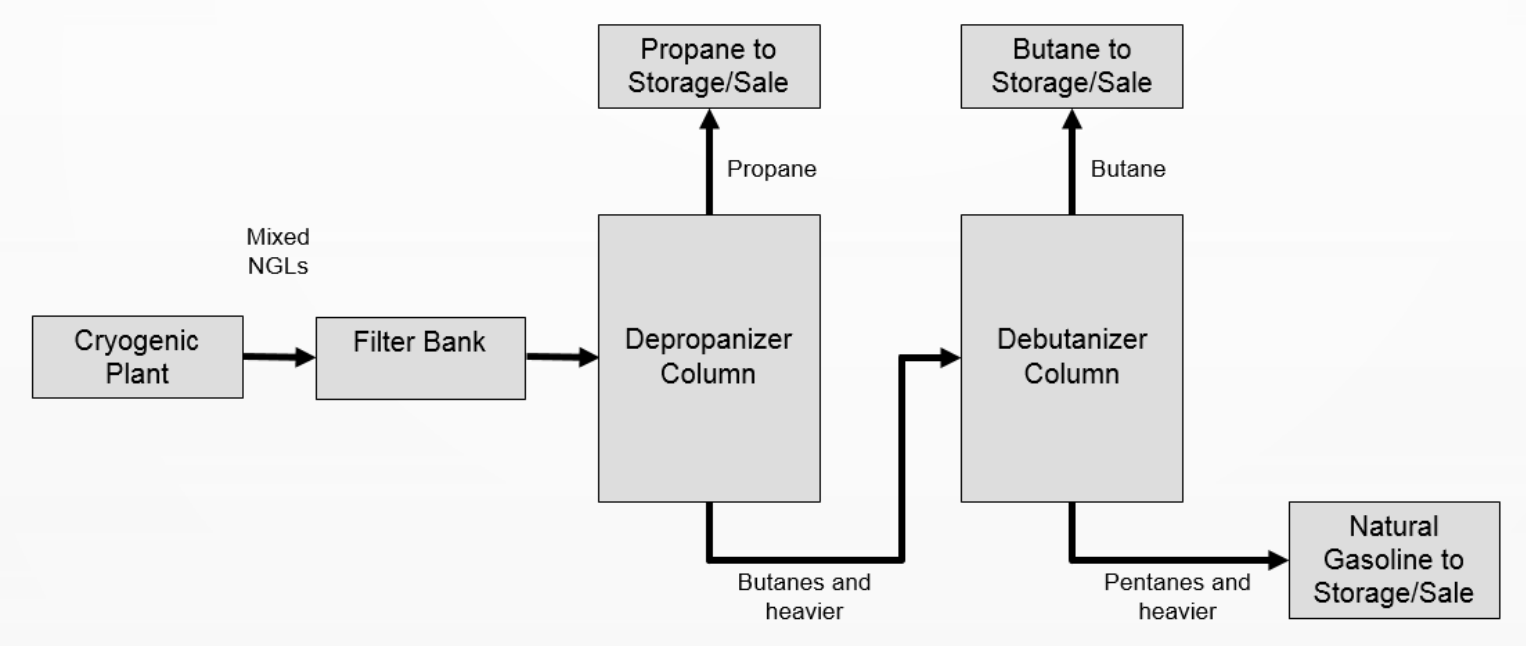

Figure 3: MGC Ohio River Fractionation Plant Process Flow Diagram

The Ohio River Fractionation Plant produces four primary products for sale to downstream customers: Propane, Butane, Natural Gasoline, and Y-grade (mixed NGLs). These are used as fuels or feedstocks for additional refining processes or blending. At the time of the initial survey, these products were being loaded and sold to customers via truck loading operations only. The quantity being loaded varied dependent upon production, storage capacity, truck loading rack capacity, and customer availability. Storage tanks for all four products were maintained on site and were in dedicated service to the product assigned to a given tank.

\section{How NORM reaches the facility}

Historically, the presence of Naturally Occurring Radioactive Material (NORM) has been a recognized issue in gulf-coast and western refineries; however, few companies have evaluated NORM exposure risk to personnel in the newly-developed Marcellus and Utica Shale gas fields. At the time of this study, no other studies had been published which assessed the exposure risk to personnel working on and around natural gas processing equipment in this region. This lack of published research presented an opportunity to assess the NORM hazard in this unique operating area and develop proactive measures to protect employees against the hazards of NORM at the Ohio River Fractionation Plant.

Due to the unique make-up of the Marcellus and Utica Shale formations, combined with the geologic distribution of uranium and thorium daughters in the region (radium-226 and radium-228), water-soluble radium isotopes enter the gas stream at unknown concentrations during the fracturing process of hydraulically fractured wells. While water is removed from the gas stream between the well head and the 
fractionation plant, some of these radium daughters have already decayed to radon or precipitated into particulate forms (lead, polonium, and bismuth isotopes) of insoluble radioactive compounds. The radon gas and the insoluble radioactive compounds are then entrained in the gas stream under pressure until they are deposited either within the pipeline itself or within a processing plant where they form scale or are caught in filter banks, strainers, pump screens/pumps, or other process equipment. Radon gas remains in the gas stream and is further concentrated into the propane stream during the fractionation process due to temperature and pressure cut points where it can then further decay to particulate forms downstream due to the short half-life of the radon. (IOGP, 2016)

Since the produced NORM is undergoing constant radioactive decay from the time it travels from the gas reservoir downstream into processing equipment within the plant, multiple forms of ionizing radiation are produced. Due to the decay series and half-lives of the radon daughters found in the Marcellus Shale, alpha, beta, and gamma radiation are all found simultaneously in the gas stream. The decay series and decay products for radium-226 and radium-228 are listed in Table 1. Although alpha and beta radiation cannot penetrate steel piping or equipment, surveying for gamma radiation on the outside of equipment is used as an indicator of the presence of alpha and beta emitters as scale or sludge on the inside.

The fractionation process is controlled by both the pressure and temperature of the feed as it travels through the fractionation column (Leffler, 2008). MGC considers this operating information to be propriety and therefore it was not made available for the purposes of this study. However, based on the relative boiling points of the feed components (methane, ethane, propane, butane, pentane, and natural gasoline) as compared to radon shown in Table 2, it can be inferred that due to the close boiling points of radon and propane, the radon will be favorably selected into the propane cut from the fractionation process. This translates to higher risk of NORM contamination in equipment in propane service. 
Table 1: Radioactive Decay Series (WNA, 2016)

\begin{tabular}{|c|c|c|c|c|c|}
\hline \multicolumn{3}{|c|}{ Uranium Decay Series ${ }^{1}$} & \multicolumn{3}{|c|}{ Thorium Decay Series ${ }^{1}$} \\
\hline Element & Decay Product & Half-Life & Element & Decay Product & Half-Life \\
\hline U-238 & alpha & $4.5 \times 10^{9} \mathrm{yr}$. & Th-232 & alpha & $1.4 \times 10^{10} \mathrm{yr}$. \\
\hline Th-234 & beta, gamma & 24 days & $\mathrm{Ra}-228$ & beta & $5.8 \mathrm{yr}$. \\
\hline $\mathrm{Pa}-234$ & beta, gamma & $1.17 \mathrm{~min}$. & Ac-228 & beta, gamma & $6.1 \mathrm{hr}$. \\
\hline U-234 & alpha & $2.5 \times 10^{5} \mathrm{yr}$ & Th-228 & alpha & $1.9 \mathrm{yr}$. \\
\hline Th-230 & alpha & $80,000 \mathrm{yr}$. & Ra-224 & alpha, gamma & 3.6 days \\
\hline Ra-226 & alpha, gamma & 1602 yr. & $\mathrm{Rn}-220$ & alpha & $55 \mathrm{sec}$. \\
\hline Rn-222 & alpha & 3.8 days & Po-216 & alpha & $0.15 \mathrm{sec}$. \\
\hline Po-218 & alpha & $3 \mathrm{~min}$. & $\mathrm{Pb}-212$ & beta & $10.6 \mathrm{hr}$. \\
\hline $\mathrm{Pb}-214$ & beta, gamma & 27 min. & $\mathrm{Bi}-212$ & $\begin{array}{l}\text { alpha, beta, } \\
\text { gamma }\end{array}$ & $61 \mathrm{~min}$. \\
\hline Bi-214 & beta, gamma & $19.7 \mathrm{~min}$. & $\begin{array}{l}\text { Po-212 } \\
\text { TI-208 }\end{array}$ & $\begin{array}{l}\text { alpha } \\
\text { beta, gamma }\end{array}$ & $\begin{array}{l}0.3 \times 10^{-6} \mathrm{sec} . \\
3 \mathrm{~min} .\end{array}$ \\
\hline Po-214 & alpha & $1.6 \times 10^{-4} \mathrm{sec}$ & $\mathrm{Pb}-208$ & none & stable \\
\hline $\mathrm{Pb}-210$ & beta, gamma & $22 \mathrm{yr}$. & \multirow{4}{*}{\multicolumn{3}{|c|}{ 1-Radioactive decay proceeds down the table }} \\
\hline Bi-210 & beta & 5 days & & & \\
\hline Po-210 & alpha & 138 days & & & \\
\hline $\mathrm{Pb}-206$ & none & stable & & & \\
\hline
\end{tabular}


Table 2: Boiling Points of Feed Components

\begin{tabular}{ll}
\hline Feed Component & Boiling Point $\left({ }^{\circ} \mathrm{C}\right)$ \\
\hline Methane & -161.5 \\
Ethane & -89.0 \\
Cut & \\
Radon & -61.9 \\
Propane & -42.0 \\
Cut & \\
Butane & -1.0 \\
Cut & \\
Natural Gas Condensate (C5/C6+) & $>36.1$ (pentane) \\
(Natural Gasoline) &
\end{tabular}

\section{Health \& Exposure Risks}

The two primary exposure routes to ionizing radiation from NORM are internal exposure and external exposure. Internal exposure occurs when radioactive material is ingested or inhaled and emitted energy from that material passes through internal tissues causing damage (typically alpha and beta radiation). External exposure occurs when radioactive material remains outside the body and emitted energy passes through clothing, skin, and tissues causing damage (typically gamma radiation). Regardless of exposure type, the cancer risk for ionizing radiation exposure correlates strongly with dose, particularly at higher doses, although it may vary based on the type of tissue exposed. (IOGP, 2016) Readings associated with NORM typically do not reach these higher exposure thresholds. However, both the United States Environmental Protection Agency (EPA) and the United States Nuclear Regulatory Commission (NRC) accept the "linear, no threshold" (LNT) model for radiation protection into their regulatory framework. This model, while somewhat controversial, extends the linear relationship between radiation dose and occurrence of cancer that occurs at higher doses down to low levels of ionizing radiation exposure. Ultimately, the model states that there is no safe level of ionizing radiation exposure, and that even at low levels, states there is a clear dose-response relationship regarding cancer risk.

This LNT model is also supported by the seventh edition of the Biologic Effects of lonizing Radiation (BEIR) report, published by the National Academies. This report discusses the difference between the acute tissue damage caused by high doses of ionizing radiation versus the chronic effects of long-term exposure to low levels of ionizing radiation which are experienced by NORM workers and other industrial radiation workers. This report addresses the difficulties of statistically estimating the risk of cancer at low 
doses, which they define at $100 \mathrm{mSv}$ (equal to $10 \mathrm{rem}$ ), however, based on the body of research currently available, accepts an increased risk of cancer and leukemia even at low doses. (USA NRC, 2006)

The primary exposure concern for NORM workers is internal exposure to alpha and beta emitters via inhalation and ingestion. NORM scale or sludge is typically wet and non-friable when equipment is initially opened. However, due to the various maintenance activities and tasks performed on the inside of the equipment, as this material dries it is disturbed throughout the process and becomes both friable and airborne. This increases the potential for inhalation as well as deposition on the employee's skin or clothing, where it can then be ingested. Once ingested or inhaled, the material continues to emit ionizing radiation internally, causing damage to the tissue. (IOGP, 2016) Employees in a facility with NORM also spend time near equipment that emits low levels of gamma radiation due to NORM contamination in the equipment or product itself. This will contribute to the employee's annual dose of ionizing radiation, putting them at a slightly increased risk for cancer based on this model.

\section{Regulatory Requirements \& Radiologic Protection Principles}

There are no federal NORM-specific regulations in effect in the United States at the time of this publication; NORM-specific regulations fall to the individual states to establish. The Ohio River Fractionation Plant is not located in a state with a NORM-specific regulation, nor were there any other state-specific laws in place at the time of the survey regarding handling, disposal or work practices for NORM waste or NORM-contaminated equipment. While there are no federal NORM-specific regulations, there is however, an OSHA standard for lonizing Radiation, 29 CFR 1910.1096. This standard's requirements apply to ionizing radiation exposure not otherwise regulated by the Nuclear Regulatory Commission in 10 CFR Part 20, including NORM. In the lonizing Radiation standard, OSHA mandates occupational exposure limits for gamma radiation and airborne radioactive material (including alpha and beta radiation-emitting isotopes) for employees entering restricted areas. In the lonizing Radiation Standard, restricted areas are identified as areas where "access is controlled by the employer for the purposes of protection of individuals from exposure to radiation or radioactive materials". The standard also lists requirements for employee monitoring, designation and labeling of radiation areas, evacuation and warning signals, notification of incidents, and recordkeeping.

The occupational dose limits enforced by OSHA via the lonizing Radiation standard are adopted from the Nuclear Regulatory Commission's (NRC) 10 CFR Part 20 Standards for Protection against Radiation. While the NRC does not have regulatory authority over NORM, they are considered an expert source of information on radiation protection principles and health physics data due to their role in regulating source material, byproducts, and other special nuclear material. Regarding protection for non-occupational exposures (members of the public) and in situations where OSHA does not provide regulatory guidance, 10 CFR Part 20 can provide useful information for radiation protection. 
To this point, OSHA's "General Duty Clause" (29 USC 654) requires that employers provide a workplace that is "...free from recognized hazards that are causing or are likely to cause death or serious physical harm..." In the situations where the OSHA lonizing Radiation standard lacks regulatory guidance, MGC would still be required to act to protect their employees from harm due to ionizing radiation exposure. Using the regulatory guidance in 10 CFR Part 20, combined with information from robust state-specific NORM regulations in Texas and Louisiana, many best practices can be identified for working on and around NORM-contaminated equipment. MGC owned facilities in other states with NORM regulations, and had previously developed a written company NORM program based off the regulatory requirements of Louisiana and Texas. This standard met some best practices for working on and around NORMcontaminated equipment in the workplace, but still had opportunities to put additional protections in place.

Lastly, the concept of ALARA, or "as low as reasonably achievable" should be considered. (Standards for Protection Against Radiation, 2016) This is the most basic of all radiologic protection principles and involves using all reasonable methods to minimize or eliminate radiation exposures (doses) and releases of radioactive materials. This is primarily done by using time, distance, and shielding. These simple principles are used to decrease the dose a worker receives by 1.) Reducing the amount of time they spend around radioactive materials, therefore reducing dose; 2.) Taking advantage of the inverse square law, where energy levels will decrease with distance from the source; and 3.) Applying shielding which absorbs energy and reduces the amount of radiation received by the worker. These principles are simple yet effective tools for radiologic protection, including NORM. (USA USNRC)

\section{Exposure Monitoring for Alpha and Beta Emitters}

As mentioned above, OSHA's lonizing Radiation standard covers exposure to airborne radioactive material in 29 CFR 1910.1096(c)(1) by incorporating the occupational exposure limits from Table 1 of Appendix B to 10 CFR Part 20. These occupational exposure limits are radionuclide-specific and are listed as annual limits on intake (ALIs) and derived air concentrations (DACs). The ALI is an annual intake limit via ingestion or inhalation which would result in either a committed effective dose equivalent of 5 rems or a committed dose equivalent of 50 rems to an organ or tissue. Per the NRC, the committed dose equivalent $(C D E)$ is the dose to organs or tissues received from the intake of radioactive material by an individual during the following 50 years from the time of the exposure (dose to a tissue or organ). Closely related to the CDE, the committed effective dose equivalent (CEDE) is the sum of the committed dose equivalent to irradiated organs and tissues using weighting factors as defined by the NRC (summation of doses allowed to various organs) (Standards for Protection Against Radiation).

The DAC is the more useful value for air monitoring, specifically, it is the concentration of a single radionuclide uniformly in air that if breathed by an employee doing light work (breathing $2 \times 10^{4} \mathrm{ml} / \mathrm{min}$ ) for 
a 2,000-hour working year would result in the employee inhaling one annual limit on intake (ALI) dose. The relationship is demonstrated in the following equation:

$$
D A C(\mu C i / \mathrm{ml})=\frac{A L I(\mu C i)}{(2000 \mathrm{hrs} / \mathrm{yr}) \times(60 \mathrm{~min} / \mathrm{hr}) \times\left(2 \times 10^{4} \mathrm{ml} / \mathrm{min}\right)}
$$

Figure 4: ALI and DAC relationship

Personal air monitoring for alpha and beta-emitting particulate can be performed using a sampling pump and filter cassette train. There are only a few select laboratories which will then process and analyze these samples in order to compare to the ALI and DAC. This air monitoring will quantitatively cover the employee's alpha and beta exposure risk due to NORM, which is not captured by other personal dosimetry devices for gamma exposure such as film badges, Thermoluminescent (TLD) detectors, or digital dosimeters. 


\section{Methodology}

Two primary approaches were taken to assessing the NORM exposure risk at the Ohio Valley Fractionation Plant. The principal focus of this study was a physical survey of the facility for gamma radiation. In addition to the physical survey, a partial qualitative exposure assessment was performed for the site which included identifying similar exposure groups and prioritizing high risk tasks for additional risk assessment.

\section{Facility Survey for Gamma Radiation}

The Ohio River Fractionation Plant was surveyed for gamma radiation as a surrogate indicator of potential alpha and beta NORM scale or particulate inside process equipment. The survey was performed during routine operations at the existing portions of the site at the time of the study. No industrial radiography occurred while the equipment surveying took place to eliminate false or skewed data. The survey was performed using a GammaRAE IIR within calibration from the manufacturer. Background radiation levels were initially established in areas non-adjacent to pipeline or process equipment before surveying began and was found to be $9 \mu \mathrm{R} / \mathrm{hr}$ on average.

To survey the facility, the entire length of all major process vessels, equipment, piping, and storage tanks were screened and representative measurements taken at regular intervals in $\mu \mathrm{R} / \mathrm{hr}$ relative to the background and recorded on a plot plan of the facility. Additional measurements were taken in areas with filter banks, strainers, and pumps, which are likely to accumulate NORM scale or particulate. These locations are points of potential employee exposure due to both planned and emergency maintenance tasks, and were prioritized throughout this study. Each piece of equipment was surveyed by holding the detector approximately 0.5 inches from the exterior surface of the equipment and taking a representative area sample. Over 300 total readings were recorded during this survey. For the purposes of this report, only the peak reading for each piece of equipment will be listed.

\section{Exposure Assessment}

To perform the initial qualitative exposure assessment for the site, personnel from operations, maintenance, instrumentation, and the quality control lab were interviewed regarding their routine duties and tasks they perform including the duration and frequency of these tasks. Observations were made of these tasks when possible, and controls in place were noted. This data was used to generate preliminary similar exposure groups for the facility. This information gathering for the initial qualitative exposure assessment was then combined with the quantitative survey data to make additional data collection recommendations and direct sampling efforts for speciation of alpha and beta emitters. 


\section{Results}

This section details the facility survey for gamma radiation in detail, including quantitative results for specific process equipment, which, combined with the initial qualitative exposure assessment data collected, were used to generate detailed recommendations.

The survey of the Ohio River Fractionation Plant began where the feed pipeline entered the facility from the upstream MGC Cryogenic Plant. The feed entering the facility produced readings between 13-21 $\mu \mathrm{R} / \mathrm{hr}$ above background. Downstream from the feed line is the filter bank intended to catch any particulate from the feed prior to entering the process equipment inside the Ohio River Fractionation Plant. The inlet filter bank had elevated NORM readings, at $630 \mu \mathrm{R} / \mathrm{hr}$.

Continuing downstream, the feed then enters the first fractionation column and reflux/reboiler loop of the fractionation process, the depropanizer. Associated equipment readings are in Table 3 below.

Table 3: NORM Readings for Depropanizer and Associated Equipment

\begin{tabular}{ll}
\hline Equipment ID/location & Peak Reading $(\mu \mathrm{R} / \mathrm{hr})$ \\
\hline Depropanizer Reboiler & 214 \\
5 ' out from Depropanizer Reboiler (midline) & 49 \\
Depropanizer Column (Outside Surface) & 25 \\
Overhead Depropanizer Accumulator & Not surveyed (no access) \\
Depropanizer Accumulator Pumps Feed Piping & 102 \\
Depropanizer Accumulator Pump A (Offline) & 71 \\
Depropanizer Accumulator Strainer A (Offline) & Not surveyed \\
Depropanizer Accumulator Pump Elbow A (Offline) & Not surveyed \\
Depropanizer Pump A Discharge Piping (Offline) & Not surveyed \\
Depropanizer Accumulator Strainer B (Running) & 4611 \\
Depropanizer Accumulator Pump B (Running) & 503 \\
Depropanizer Accumulator Pump Elbow B (Running) & 402 \\
Depropanizer Pump B Discharge Piping (Running) & 150 \\
Propane Reflux Piping \& Valves (Running) & 277 \\
Propane Line to Storage Tanks (Running) & 64 \\
\hline
\end{tabular}


The next fractionation column and reflux loop in the process is the Debutanizer. At this point, most the propane cut is already removed, so NORM readings were expected to be substantially lower than the propane-service equipment. Readings for the associated equipment are summarized in Table 4 below.

Table 4: NORM Readings for Debutanizer and Associated Equipment

\begin{tabular}{ll}
\hline Equipment ID/location & Peak Reading $(\mu \mathrm{R} / \mathrm{hr})$ \\
\hline Debutanizer Reboiler & 196 \\
Overhead Debutanizer Accumulator & Not surveyed (no access) \\
Debutanizer Column (Outside Surface) & 13 \\
Debutanizer Accumulator Pumps Feed Piping & 13 \\
Debutanizer Accumulator Pump A (Offline) & 8 \\
Debutanizer Accumulator Strainer A (Offline) & 10 \\
Debutanizer Accumulator Pump Elbow A (Offline) & 10 \\
Debutanizer Pump A Discharge Piping (Offline) & 8 \\
Debutanizer Accumulator Strainer B (Running) & 7 \\
Debutanizer Accumulator Pump B (Running) & 7 \\
Debutanizer Accumulator Pump Elbow B (Running) & 7 \\
Debutanizer Pump B Discharge Piping (Running) & 6 \\
Butane Reflux Piping and Valves (Running) & 5
\end{tabular}




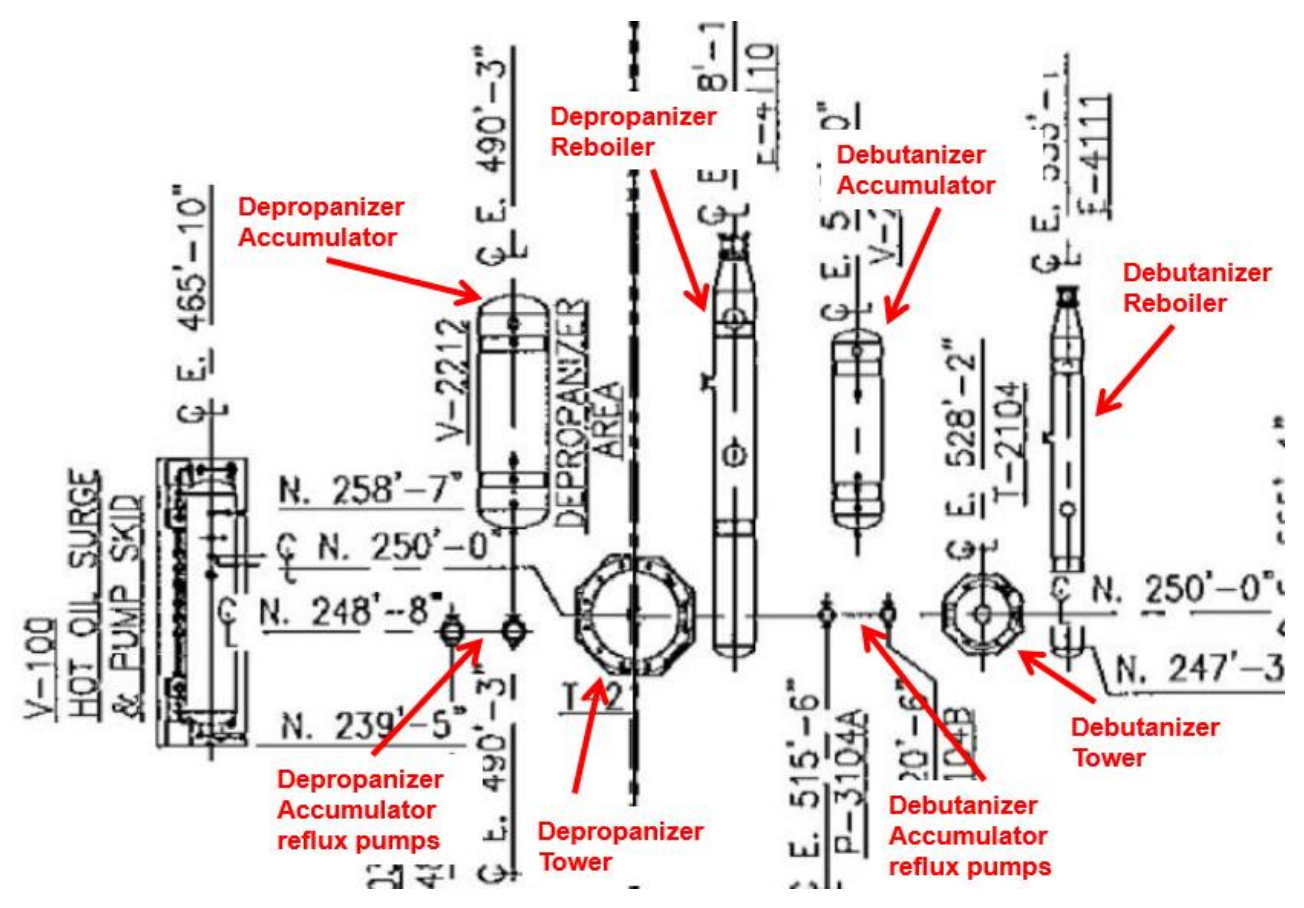

Figure 5: Depropanizer and Debutanizer Plot Plan

The major equipment and associated piping surveyed from Tables 3 and 4 is shown in Figure 5 . The Ohio River Fractionation Plant has limited storage capabilities for its products, with 6 NGL storage tanks, 6 propane storage tanks, 2 butane storage tanks, and 2 natural gasoline storage tanks, seen in Figure 6 below. There were 3 pumps associated with this equipment in service and accessible at the time of the survey (see Table 5 for readings).

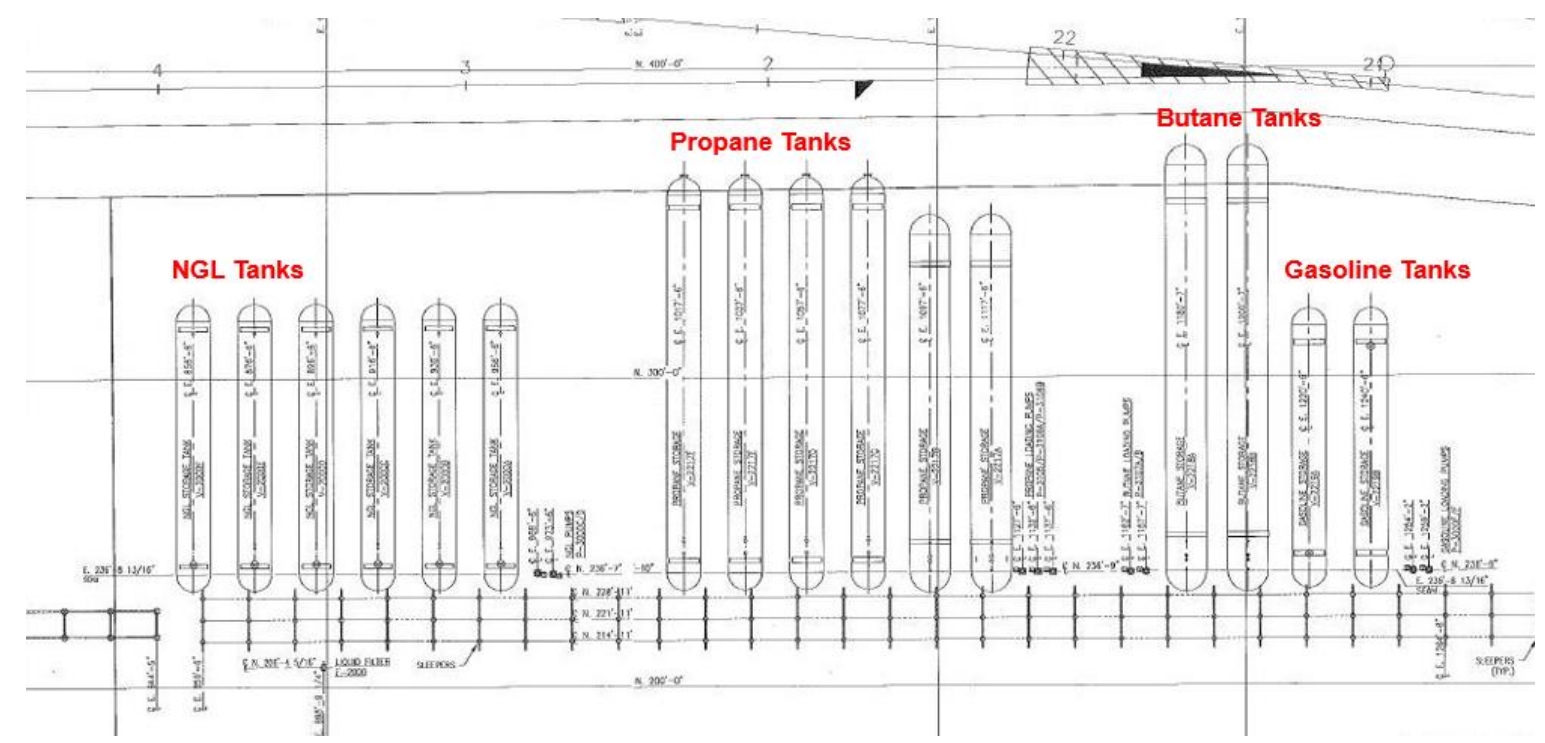

Figure 6: Storage Tank Plot Plan 
Table 5: NORM Readings for Product Storage

\begin{tabular}{llll}
\hline Equipment ID/location & Peak Reading & Equipment ID/location & Peak Reading \\
& $(\mu \mathrm{R} / \mathrm{hr})$ & $(\mu \mathrm{R} / \mathrm{hr})$ \\
\hline NGL Storage Tank 1 & 41 & Propane Storage Tank 3 & 148 \\
NGL Tank 1 Inlet & 16 & Propane Tank 3 Inlet & 89 \\
NGL Storage Tank 2 & 44 & Propane Storage Tank 4 & 159 \\
NGL Tank 2 Inlet & 38 & Propane Tank 4 Inlet & 57 \\
NGL Storage Tank 3 & 57 & Propane Storage Tank 5 & 64 \\
NGL Tank 3 Inlet & 25 & Propane Storage Tank 6 & 100 \\
NGL Storage Tank 4 & 60 & Butane Storage Tank 1 & Background \\
NGL Tank 4 Inlet & 47 & Butane Storage Tank 2 & Background \\
NGL Storage Tank 5 & 66 & Gasoline Storage Tank 1 & Background \\
NGL Tank 5 Inlet & 59 & Gasoline Storage Tank 2 & Background \\
NGL Storage Tank 6 & 67 & Pumps: NGL tanks to truck rack & 262 \\
NGL Tank 6 Inlet & 49 & Pumps: Propane tanks to truck rack & 198 \\
Propane Storage Tank 1 & 132 & Pumps: Butane tanks to truck rack & 16 \\
Propane Tank 1 Inlet & 47 & & \\
Propane Storage Tank 2 & 104 & & \\
Propane Tank 2 Inlet & 47 & & \\
\hline
\end{tabular}

At the time of the survey, the truck loading rack was only partially operational and in use for loading. Therefore, only one bay and associated loading piping was surveyed due to its high frequency of use. Additionally, due to ongoing U.S. Department of Transportation (DOT) compliance concerns, a tanker truck loading propane was surveyed prior to and after loading to determine if ionizing radiation was detectable in the site's finished propane product. These readings can be found in table 6 below. 
Table 6: NORM Readings for Product Loading Area

\begin{tabular}{ll}
\hline Equipment ID/location & Peak Reading $(\mu \mathrm{R} / \mathrm{hr})$ \\
\hline Shared Truck Rack Inlet Line & 176 \\
Butane Loading Line & 14 \\
Propane Loading Line & 101 \\
NGL (Y-grade) Loading Line & 31 \\
Gasoline Loading Line & Background \\
Empty Propane Truck & 43 \\
Loaded Propane Truck & 135 \\
\hline
\end{tabular}

Overall, the gamma survey indicated that the majority of the equipment on site in mixed NGL or propane service produced readings that exceeded the company's internal limit of $50 \mu \mathrm{R} / \mathrm{hr}$, the level at which implementing MGC's corporate NORM Procedure is required. Additionally, the data collected from propane truck loading activities (Table 6) show that the finished propane product itself contains gammaemitting NORM materials in addition to what may be deposited throughout the equipment on site. While this data has implications on DOT compliance, it was not the focus of this study. However, it does show that there is a potential for lower NORM readings once equipment is pressure-free and de-inventoried. 


\section{Discussion of Results}

\section{Similar Exposure Groups}

There are six primary similar exposure groups (SEGs) identified by the partial qualitative exposure assessment performed at the Ohio River Fractionation Plant. These are listed in Table 6 below. Of these six SEGs, only two SEGs performed tasks that placed them in the highest exposure risk group for alpha, beta, and gamma radiation exposure at the Ohio River Fractionation Plant: Maintenance Technicians and Turnaround Maintenance personnel. Three additional SEGs, Plant Operations Technicians, Truck Loading Operations Technicians, and Instrumentation Technicians work around equipment that could put them at risk for gamma radiation exposure. The last SEG, Quality Control Lab Technicians had the lowest exposure risk for any kind of radiation exposure, spending very little to no time in process areas.

Table 7: Ohio River Fractionation Plant Similar Exposure Groups

\begin{tabular}{ll}
\hline Radiation Type & Similar Exposure Groups \\
\hline \multirow{2}{*}{ Alpha, Beta, Gamma } & Maintenance Technicians \\
& Turnaround Maintenance Personnel \\
& Plant Operations Technicians \\
Gamma Only & Truck Loading Operations Technicians \\
& Instrumentation Technicians \\
Low/No Risk of Exposure & Quality Control Lab Technicians \\
\hline
\end{tabular}

Maintenance technicians at the plant are MGC employees who perform a variety of routine tasks to maintain the equipment at the Ohio River Fractionation Plant. Based off employee interviews and the gamma survey performed, three tasks were initially identified that held the highest exposure potential to alpha and beta emitters for this SEG. These tasks include cleaning and/or changing of the inline strainers on the Depropanizer reflux line (performed quarterly), pig retrieval of the 8" pig on the inlet line from the upstream MGC Cryogenic Plant (performed as needed/infrequent), and filter changes on the inlet filter bank on the NGL feedstock line for the Ohio River Fractionation Plant (performed twice a year). These tasks involve working on equipment that had the highest gamma readings taken during the survey of the facility and are performed on equipment that has the potential to accumulate scale or sludge that could contain alpha and beta emitters. These tasks had no controls currently in place to protect the employees against exposure, and employees had not received training on NORM hazards from MGC at the time of 
the assessment. Additionally, these employees routinely work around equipment that has detectable gamma readings above background, potentially putting them at risk for exposure to gamma radiation during their routine rounds.

Additional tasks with exposure risk to alpha and beta emitters were identified for the Maintenance Technicians following the conclusion of the initial on-site study. These tasks include several activities with the potential to make particulate NORM friable in the work area such as grinding, buffing, cutting, welding, machining, and unbolting equipment in NORM service. Line breaks, equipment draining/purging and equipment removal/replacement were also identified as activities with exposure risk. These activities were not assessed at the time of this study and will require additional information for proper exposure assessment.

The other SEG with the highest exposure potential for alpha and beta emitters, Turnaround Maintenance personnel, was not identified at the time of the initial survey, however, based on industry data, all petrochemical facilities require extended outages, or "turnarounds", on a regular cycle, typically occurring every 3 to 5 years, to perform large scale maintenance, repairs, and upgrades to equipment. These turnarounds are typically performed by regular or contract maintenance personnel, and involve a myriad of tasks with potential exposure to NORM like the Maintenance Technicians. These tasks include blinding equipment, entering equipment for inspection and repairs, removing/replacing equipment such as pumps, welding and other activities that could produce friable NORM, and. Since the facility was relatively new at the time of this survey, no turnarounds had been performed at the site. Additional information will be required to properly assess the potential risk for tasks associated with future turnarounds at the Ohio River Fractionation Plant. The potential exposure risk and any correlated recommendations must be kept in consideration during scope planning or other turnaround pre-planning activities, which are typically performed at least a year in advance.

While Maintenance Technicians perform nearly all work on the site that involves equipment opening, Operations Technicians and Truck Loading Operations Technicians spend a large period of time throughout the day in the process unit, itself, or in the truck rack performing routine inspections and process sampling activities that places them on or near equipment with detectable gamma radiation levels relative to background. There is no signage indicating NORM radiation areas in the facility or training in place to make these employees aware of the radiation hazard present at various site locations and inside equipment. These employees typically spend at least half their shift working in the units, so additional information will be required to fully assess their exposure potential throughout the day.

Instrumentation Technicians also spend most of their day inside the plant working in all areas of the facility, which puts them near equipment with gamma radiation exposure potential relative to background due to NORM; however, only a few instrumentation tasks were observed during the course of this study. 
While the primary risk for Instrumentation Technicians may be gamma exposure, there may be other hazards not considered here.

Employees in the last SEG, Quality Control Lab Technicians, do not spend any time in the process areas of the plant during their routine duties at the Ohio River Fractionation Plant. Their duties primarily consist of running tests on the samples operations takes inside the quality control laboratory on site and maintaining the sampling cylinders for operations. It is unlikely that these activities would contribute to any NORM radiation exposure for their SEG.

The goal of this partial qualitative exposure assessment was make an initial identification of SEGs for the site as they relate to exposure risk. For those SEGs where collection of additional information is needed, a more thorough task analysis including observations, detailed interviews, and qualitative risk assessments, including exposure monitoring, would be required to properly assess employee risk in these SEGs.

\section{Exposure Limits \& Employee Training}

As previously stated, the Ohio River Fractionation Plant does not reside in a state with a state-specific NORM regulation, nor does a federal NORM regulation exist. However, MGC established a corporate NORM Procedure in October 2011 which applies to all sites with equipment exceeding the company's internal limit of $50 \mu R / h r$ (based on LAC 33:XV.1410). The company NORM procedure details requirements for maintenance activities involving handling, storage, and disposal of NORM. At a $50 \mu \mathrm{R} / \mathrm{hr}$ continuous exposure rate, over a forty-hour work week for 50 weeks a year, accounting for two weeks of vacation, an employee's dose would equate to $100 \mathrm{mR} /$ year. This dose, $100 \mathrm{mR} / \mathrm{year}$, is the NRC's maximum annual dose for non-radiation workers, who are considered "individual members of the public" under the NRC (Standards for Protection Against Radiation, 2016). This regulation also states that the dose to individual members of the public from external sources of radiation in an unrestricted area cannot exceed $0.002 \mathrm{R}$ in any one hour (or $2000 \mu \mathrm{R}$ ). These limits were set to protect against ionizing radiation exposure due to source material, however, they can be used as a best practice limit for ionizing radiation exposure control (Standards for Protection Against Radiation).

Since the radiation hazard cannot be eliminated, and MGC employees are required to enter areas exceeding $50 \mu \mathrm{R} / \mathrm{hr}$ to perform routine work duties, adherence to recommended NRC dose limits would require these employees to be trained as occupational radiation workers. This would ensure that the higher dose limits assigned to occupational radiation workers would apply to MGC's Ohio River Fractionation Plant employees. The exposure limits for occupational radiation workers are higher than what is allowed for individual members of the public since occupational radiation workers are trained to understand radiologic protection principles. According to the NRC, occupational radiation workers may be 
exposed up to $5 \mathrm{R} /$ year $(5,000,000 \mu \mathrm{R} /$ year) except for a declared pregnant woman who is a radiation worker. If pregnancy is declared in writing, this limit is lowered to 0.5 rem for the duration of the pregnancy $(500,000 \mu \mathrm{R} / 9$ months or approximately $50,000 \mu \mathrm{R} / \mathrm{month})$. (Standards for Protection Against Radiation, 2016)

This approach would ensure that site personnel entering areas exceeding $50 \mu \mathrm{R} / \mathrm{hr}$ understand and are trained on the risk of working around ionizing radiation due to NORM. This would include work around the Depropanizer Accumulator Strainer B, which had the site's highest surface readings of $4611 \mu \mathrm{R} / \mathrm{hr}$. An employee working in direct contact with this equipment for a forty-hour work week for 50 weeks a year would potentially receive an annual dose of $9.22 \mathrm{R} / \mathrm{yr}$. However, this is not reflective of the employee's actual work duties in the plant, so the true annual received dose can be expected to be much lower. For declared pregnant workers, additional controls or monitoring would be required to closely monitor their dose.

Alternatively, MGC could chose to perform dosimetry to evaluate the dose of ionizing radiation received by employees in similar exposure groups and then decide on which SEGs to train as occupational radiation workers. However, consideration must be made regarding training a portion of employees as occupational radiation workers due to the NRC exposure limit of $0.002 R(2000 \mu R)$ in any one hour (Standards for Protection Against Radiation, 2016). This limit would be quickly exceeded when working directly around the Depropanizer Accumulator Strainer B when the equipment is inventoried with product, which would cover some routine work tasks across the established preliminary SEGs. However, this was the only equipment with surface readings exceeding $2000 \mu \mathrm{R} / \mathrm{hr}$, so there is a limited application for this requirement. Using the $50 \mu \mathrm{R} / \mathrm{hr}$ limit as a trigger for occupational radiation worker safety training would provide adequate training coverage for any affected employees.

\section{Written Program}

The controls detailed in the MGC NORM Procedure are adequate in maintaining the minimum layers of protection for employees working at a NORM facility with the exception of employee training detailed previously in this section. The procedure itself is based on a combination of state NORM regulations from Texas, Louisiana, and New Mexico. The written procedure addresses the following information in regards to NORM: Responsibilities, Controlled Work Areas, Equipment Maintenance Procedures (including ventilation), Personnel Procedures and Monitoring (including personal protective equipment and respiratory protection), Decontamination, Waste Handling/Storage, Auditing, Surveys, and Recordkeeping Procedures. When a gap assessment was performed on MGC's written NORM program, opportunities were identified around employee training, recordkeeping process, and hazard communication as compared to industry best practices. These are detailed in the following section, Recommendations. 


\section{Recommendations}

The following are recommended for the MGC Ohio River site following a thorough review of the site's written NORM Procedure, including comparison to both OSHA regulatory requirements, best practices from NRC and Texas State NORM regulations, as well as other practices found in the petrochemical industry. The goals of these recommendations are not only to ensure that MGC maintains compliance with applicable laws (such as 29 CFR 1910.1096), but also to suggest additional reasonable measures to protect employees using ALARA principles and industry best practices.

\section{Equipment}

1. Purchase of Survey Equipment:

Based on the survey results at this location, it is recommended that MGC purchase radiation survey equipment for the Ohio River Fractionation Plant. This should include a survey meter or meters capable of detecting both alpha/beta radiation as well as gamma radiation. This equipment should be kept within the manufacturer's recommended calibration interval and records of calibration should be maintained according to MGC's record retention policy.

\section{Training \& Hazard Communication}

1. Radiation Safety Officer Training

At least one employee on site should be trained to the level of industrial radiation safety officer (RSO). This will ensure that the site can assess radiation risk at the local level and appropriately calculate and maintain exposure records for employees working on the site. This coursework should be targeted towards NORM as appropriate.

2. Occupational Radiation Worker Training

Due to the potential for radiation exposure on site, MGC should commence an initial and thereafter annual refresher occupational radiation worker training program for their Plant Operations Technicians, Maintenance Technician and Turnaround Maintenance Personnel SEGs, and others as deemed appropriate by dosimetry or a detailed qualitative risk assessment. This should include: types of radiation including the origins of NORM, health and biological effects, ALARA principles, exposure limits, monitoring, labeling, work practices which can cause NORM to become friable, personal protective equipment, decontamination, engineering controls, emergency procedures, waste handling, and training on MGC's NORM Procedure.

3. Awareness Level Radiation Training:

In lieu of occupational radiation worker training, at a minimum, all employees on site should receive an annual awareness level radiation training course covering types of radiation (including 
basic characteristics of NORM), health effects, ALARA principles, training on the site's labeling and signage, and any restrictions regarding work activities or locations necessary.

4. Survey Equipment Training:

Safety personnel or the RSO on site should be trained to use, calibrate, and maintain radiation survey equipment in order to conduct both external and internal surveys of equipment. External training may be advisable for those performing NORM surveys, and courses are available specifically for this function.

5. Equipment Labeling:

Equipment with external surface readings of $50 \mu \mathrm{R} / \mathrm{hr}$ should be labeled with "Caution - NORM Contaminated" via labels or other means to identify the need for NORM precautions as identified in MGC's NORM Procedure. These labels should include a yellow background and magenta lettering. A file should be kept for each piece of equipment to document surveys (both internal and external) performed at that location. These records should be kept according to MGC's record retention policies, with the recommendation that they be preserved for the lifetime of the equipment.

6. Radiation Area Signage:

Any areas with readings of over $2000 \mu \mathrm{R} / \mathrm{hr}$ at one foot from the equipment should be barricaded to prevent inadvertent entry and be signed with a radiation symbol and "Caution - Radiation Area" in magenta lettering on a yellow background from all approaches. This is based on NRC requirements and is considered a best practice to protect members of the public. At a minimum, OSHA requires areas exceeding $5000 \mu \mathrm{R} / \mathrm{hr}$ and areas where the employee may receive a dose of $100 \mathrm{mR}$ over a 5 -day period $(1,667.67 \mu \mathrm{R} / \mathrm{hr}$ for a 12 -hour shift $)$ to be labeled as such.

\section{Written Program \& Procedures}

1. PPE Task Assessments:

Individual tasks with known NORM exposure risk should be evaluated and assigned PPE accordingly. A certified hazard assessment should be performed per 29 CFR 1910.132(d)(2) and kept on record for each task. These assessments may be incorporated into MGC's written NORM procedure in the form of a matrix tool for employee use.

2. Revision to MGC's Written NORM Procedure

MGC's NORM Procedure was found to provide adequate controls for performing work on NORMcontaminated equipment; however, the written program should be updated to reflect the recommendations adopted from this section with regards to training, equipment, recordkeeping, and other controls. 


\section{Risk Assessment \& Exposure Monitoring}

1. Internal Equipment Surveys:

Appropriately trained site personnel should perform and document internal equipment surveys after equipment is purged of product to determine whether potentially friable NORM may be present during maintenance work. This should be performed using a probe capable of detecting alpha and beta radiation which make of the majority of NORM particulate present in equipment. Alpha and beta are measured in disintegrations per minute, or DPM and all readings should be compared to a background reference point measured outside of process areas on site. If contamination is detected over 1000 DPM above background, the NORM PPE and controls from MGC's NORM Procedure should be utilized.

2. Additional Risk Assessment for SEGs:

The preliminary data collection conducted during this study identified additional opportunities for task observations and further qualitative risk assessment for both Turnaround Maintenance personnel and Instrumentation Technicians. Since the risk to Turnaround Maintenance personnel varies based on scope of project work, this may need to be performed following the engineering/scoping phase of any turnaround work to be performed at the site.

3. Additional Risk Assessment for Tasks:

There are several tasks not identified at the time of the initial assessment that require further qualitative risk assessment as well. These include activities with the potential to make NORM scale or sludge friable in the workplace including grinding, buffing, cutting, welding, machining, and unbolting equipment in NORM service as well as line breaks, equipment draining/purging, and equipment removal/replacement.

4. Quantitative Assessment - Gamma Radiation:

Dose due to external gamma radiation to the body should be monitored initially for representative employees from the various SEGs to determine whether there is potential to exceed the annual OSHA or the previously recommended NRC occupational dose limits. This may be done using a film badge, Thermoluminescent (TLD) detector, or a digital dosimeter. If there is potential to exceed $10 \%$ of the annual occupational limits, a quarterly monitoring program should be put in place with appropriate recordkeeping and employee notification for the SEG in question. All monitoring devices should be analyzed through a laboratory holding personnel dosimetry accreditation from the National Voluntary Laboratory Accreditation Program (NVLAP).

5. Quantitative Assessment - Alpha and Beta Emitters

Personal exposure monitoring for friable alpha and beta emitters may be performed on MGC Maintenance Technicians using a sampling pump and filter cassette during activities identified as 
high-risk during the qualitative task assessments. Samples should be analyzed at a laboratory which can identify the radionuclides of concern and report results against the DAC and ALI for the radionuclides in question. Alternatively, a radiation-licensed maintenance contractor may be brought in to perform these activities while monitoring is performed, which would ensure that no MGC employees risk exceeding allowable exposure limits without the proper training, programs, and controls already in place.

6. ALARA Assessment:

For MGC employees who will not be trained as occupational radiation workers, an ALARA assessment should be performed and documented to ensure that these employees exposure is a) below the annual dose limits for members of the general public and b) maintained as low as reasonably achievable. This may be done semi-quantitatively by determining locations where these employees will perform work, assessing the duration of time they will spend in these locations as well as the frequency, and then utilizing a radiation survey meter to take readings at these locations in order to calculate the expected dose for the year. This assessment should be posted or otherwise documented so site employees may read it. 


\section{Conclusions}

MGC requires additional training, monitoring, and written program updates to protect its employees at the Ohio River Fractionation Plant from the hazards of NORM in the workplace. Further data collection should be performed to fully assess and prioritize employee risk using a workplace qualitative exposure assessment methodology. Once the risk is prioritized, additional quantitative personal monitoring should be performed on MGC employees as directed by the exposure assessment. By utilizing industry best practices and NORM regulations from states with existing guidelines, MGC can ensure their employees' risk due to NORM is at an acceptable level. 


\section{References}

1.) Brockett, D. (2015, March 19). Penn State Extension. Natural Gas Liquids: From Wellhead to Fractionation [Webinar]. Retrieved from http://extension.psu.edu/natural-resources/naturalgas/webinars/natural-gas-liquids-from-wellhead-to-fractionation/natural-gas-liquids-fromwellhead-to-fractionation-powerpoint.

2.) Duties of Employers and Employees, 29 U.S.C. § 654, 5(a)1 (2016).

3.) International Association of Oil \& Gas Producers. (March 2016). Managing Naturally Occurring Radioactive Material (NORM) in the Oil and Gas Industry (2nd ed.). NORM Taskforce.

4.) lonizing Radiation, 29 C.F.R. Part 1910.1096 (2016).

5.) Leffler, W. L. (2008). Petroleum Refining in Nontechnical Language (4th ed.). Tulsa, OK: PennWell Corporation.

6.) Personal Protective Equipment, 29 C.F.R. Part 1910.132 (2016).

7.) Radiation Control, 25 T.A.C. $§ 289.259$ (2016).

8.) Radiation Protection, L.A.C. Title 33 Part XV (2016).

9.) Seddon, D. (2006). Gas Usage \& Value: The Technology and Economics of Natural Gas use in the Process Industries. Tulsa, OK: PennWell Corporation.

10.) Standards for Protection Against Radiation, 10 C.F.R. Part 20 (2016).

11.) United States of America, National Research Council of the National Academies. (2006). Health Risks from Exposure to Low Levels of lonizing Radiation: BEIR VII Phase 2. Washington, DC: National Academies Press.

12.) United States of America, USNRC Technical Training Center. (n.d.). Dose Standards and Methods for Protection Against Radiation and Contamination (Rev. 603).

13.) World Nuclear Association. (December 2016) Naturally-Occurring Radioactive Materials (NORM). Retrieved from http://www.world-nuclear.org/information-library/safety-and-security/radiation-andhealth/naturally-occurring-radioactive-materials-norm.aspx. 